\title{
Validation of computed tomography for measuring lung weight
}

\author{
Alessandro Protti ${ }^{*}$, Giacomo E lapichino ${ }^{2}$, Marta Milesi ${ }^{2}$, Valentina Melis ${ }^{2}$, Paola Pugni ${ }^{2}$, Beatrice Comini ${ }^{2}$, \\ Massimo Cressoni ${ }^{2}$ and Luciano Gattinoni ${ }^{1,2}$
}

\author{
* Correspondence: alessandro. \\ protti@policlinico.mi.it \\ 'Dipartimento di Anestesia, \\ Rianimazione ed Emergenza \\ Urgenza, Fondazione IRCCS Ca \\ Granda - Ospedale Maggiore Policlinico, \\ Via F. Sforza 35, 20122 Milan, Italy \\ Full list of author information is \\ available at the end of the article
}

\begin{abstract}
Background: Lung weight characterises severity of pulmonary oedema and predicts response to mechanical ventilation. The aim of this study was to evaluate the accuracy of quantitative analysis of thorax computed tomography (CT) for measuring lung weight in pigs with or without pulmonary oedema.

Methods: Thirty-six pigs were mechanically ventilated with different tidal volumes and positive end-expiratory pressures that did or did not induce pulmonary oedema. After $54 \mathrm{~h}$, they underwent thorax $\subset \mathrm{C}\left(\mathrm{CT}_{\text {in vivo }}\right)$ and were then sacrificed and exsanguinated. Fourteen pigs underwent a second thorax $\subset$ ( $\left(T_{\text {post-exsang }}\right)$ after exsanguination. Lungs were excised and weighed with a balance (balance post-exsang $_{\text {). }}$. Agreement between lung weights measured with the balance (considered as reference) and those estimated by quantitative analysis of $C T$ was assessed with Bland-Altman plots.
\end{abstract}

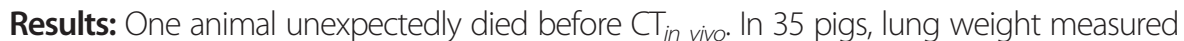

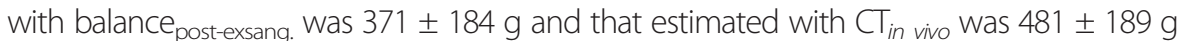
$(p<0.001)$. Bias between methods was $-111 \mathrm{~g}(-35 \%)$ and limits of agreement were -176 $(-63 \%)$ and $-46 \mathrm{~g}(-8 \%)$. Measurement error was similar in animals with $(-112 \pm 45 \mathrm{~g}$; $n=11)$ or without $(-110 \pm 27 \mathrm{~g} ; n=24)$ pulmonary oedema $(p=0.88)$. In 14 pigs with thorax $C T$ after exsanguination, lung weight measured with balance post-exsang

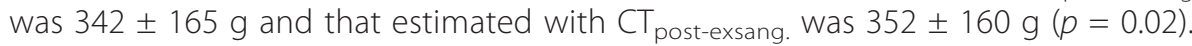
Bias between methods was $-9 \mathrm{~g}(-4 \%)$ and limits of agreement were $-36(-11 \%)$ and $17 \mathrm{~g}(3 \%)$. Measurement errors were similar in pigs with $(-1 \pm 26 \mathrm{~g} ; n=11)$ or without ( $-12 \pm 7 \mathrm{~g} ; n=3)$ pulmonary oedema $(p=0.12)$.

Conclusions: Compared to the balance, CT obtained in vivo constantly overestimated the lung weight, as it included pulmonary blood (whereas the balance did not). By contrast, CT obtained after exsanguination provided accurate and reproducible results.

Keywords: Computed tomography; Lung weight; Ventilator-induced lung injury; Pulmonary oedema

\section{Background}

During ventilator-induced lung injury and acute respiratory distress syndrome, lung weight increases as a result of inflammatory pulmonary oedema [1,2]. Exact quantification of this phenomenon can help diagnosis, prognosis and even therapy. For instance, patients with heavy (and largely recruitable) lungs benefit the most from use of high positive end-expiratory pressure [3] or prone position [4]. 
One method for estimating lung weight in vivo is quantitative analysis of thorax computed tomography (CT). Lungs are selected on CT images and their total (gas and tissue) volume and physical density (that presumably reflects relative content of gas and tissue) are measured. Lung tissue volume is derived from these two parameters. Lung tissue weight is computed assuming that the density is $1 \mathrm{~g} / \mathrm{ml}[5]$.

Selection of region of interest is crucial for quantitative analysis of CT. It is usually performed manually, based on individual judgement, and is prone to errors especially when contours are not linear and content is not homogeneous [6]. Inaccuracy is indeed less than $1 \%$ for phantoms with regular shape [7] but as high as $10 \%$ for objects with complex geometry, including human organs [8]. Oedema may act as an additional confounder as it deforms anatomy and increases inhomogeneity.

The aim of this study was to validate quantitative analysis of CT (against gravimetry) for measuring lung weight in pigs with or without pulmonary oedema.

\section{Methods}

This is a sub-study of our past $[9,10]$ and present works. Experiments complied with international recommendation [11] and were approved by the Italian Ministry of Health.

Validation of $\mathrm{CT}$ performed in living animals $\left(\mathrm{CT}_{\text {in vivo }}\right)$ for measuring lung weight Thirty-six consecutive healthy female pigs $(23 \pm 3 \mathrm{~kg})$ were mechanically ventilated with different tidal volumes and positive end-expiratory pressures under general anaesthesia (propofol [5 to $10 \mathrm{mg} / \mathrm{kg} / \mathrm{h} \mathrm{IV}$ ] and medetomidine [2.5 to $10.0 \mu \mathrm{g} / \mathrm{kg} / \mathrm{h} \mathrm{IV])} \mathrm{and}$ paralysis (pancuronium bromide [0.3 to $0.5 \mathrm{mg} / \mathrm{kg} / \mathrm{h} \mathrm{IV]}$ ). After $54 \mathrm{~h}$, thorax CT $\left(\mathrm{CT}_{\text {in vivo }}\right)$ was obtained. Animals were then sacrificed ( $\mathrm{KCl} 40 \mathrm{mEq} \mathrm{IV)}$ and exsanguinated through an incision in the inferior vena cava. Lungs were excised en bloc, dissected from the trachea, main bronchi and hilar lymph nodes, and weighted with a

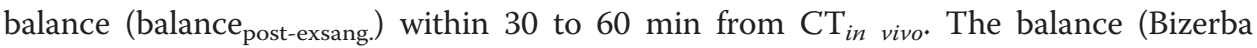
Maxima Super Elox, Bizerba, Milan, Italy) underwent periodical tests with calibrated weights. Percentage error (see below) was always $<1 \%$. Ventilator-induced pulmonary

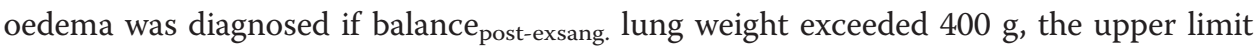
for healthy pigs of similar sex and weight $[1,9,10]$.

One animal unexpectedly died before we could obtain thorax $\mathrm{CT}_{\text {in vivo. }}$ It was immediately exsanguinated and included in the second part of the study (see below).

\section{Validation of $\mathrm{CT}$ performed after exsanguination ( $\mathrm{CT}_{\text {post-exsang.) }}$ ) for measuring lung weight}

Fourteen (out of 36) animals underwent a second thorax CT ( $\left.\mathrm{CT}_{\text {post-exsang. }}\right)$ once exsanguinated. The volume of blood removed was always quantified, whereas density $(\mathrm{g} / \mathrm{ml})$ was measured in three cases. Lungs were then excised and weighted with the balance (and pulmonary oedema was eventually diagnosed) as above.

\section{Quantitative analysis of CT}

CTs were obtained at $0 \mathrm{cmH}_{2} \mathrm{O}$ of airway pressure with the following settings: collimation, $5 \mathrm{~mm}$; interval, $5 \mathrm{~mm}$; bed speed, $15 \mathrm{~mm} / \mathrm{s}$; voltage, $140 \mathrm{kV}$; and current $240 \mathrm{~mA}$ 
(Lightspeed QXi, GE Healthcare, Madison, WI, USA). Quality controls were performed every month using standard phantoms.

Experienced operators manually countered the lung profile excluding proximal airways, large vessels and lymph nodes, mediastinum, muscles and bones and pleural effusions (Maluna 3.15, University Hospital of Goettingen, Germany).

For each voxel of interest, tissue weight was

Voxel tissue weight $=[1-($ Voxel density $/-1,000)] \times$ Voxel volume

Voxel density was expressed in Hounsfield units (HU), with values of $-1,000,0$ and $+1,000 \mathrm{HU}$ assigned to air, lung tissue (including parenchyma, blood and water) and bone, respectively. Voxel volume was $1.8 \mathrm{~mm}^{3}$.

Lung tissue weight was the sum of the weight of all selected voxels [5].

\section{Repeatability and reproducibility of quantitative analysis of thorax CT}

Thorax $\mathrm{CTs}_{\text {in vivo }}$ of one animal with and one animal without pulmonary oedema were analysed thrice by the same operator (repeatability) and once by three different operators (reproducibility).

\section{Statistical analysis}

Normality of data distribution was verified with the Shapiro-Wilk test. Results are reported as means \pm standard deviations. Difference between groups was assessed with Student's $t$ test or Mann-Whitney rank sum test. Agreement between reference (balance; gravimetry) and test (quantitative analysis of CT) methods was studied with Bland-Altman plots and analysis of correlation [12]. Percentage error was the ratio between the limits of agreement and reference measurement. Repeatability and reproducibility were expressed as coefficients of variation, the ratio between standard deviations and means. Statistical significance was defined as $p<0.05$ (SigmaPlot 11.0, Jandel Scientific Software, San Jose, CA, USA).

\section{Results}

Validation of $\mathrm{CT}$ performed in living animals ( $\left.\mathrm{CT}_{\text {in vivo }}\right)$ for measuring lung weight

In 35 pigs (11 with pulmonary oedema), lung weight was $371 \pm 184 \mathrm{~g}$ when measured with balance post-exsang. $_{\text {and }} 481 \pm 189 \mathrm{~g}(p<0.001)$ when estimated with quantitative

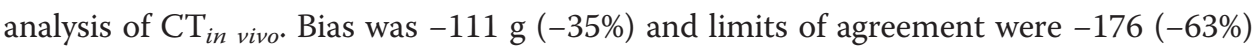
and $-46 \mathrm{~g}(-8 \%)$ (Figure 1a). Percentage error was $35 \%$ and coefficient of correlation was $0.97(p<0.0001)$ (Figure 1b).

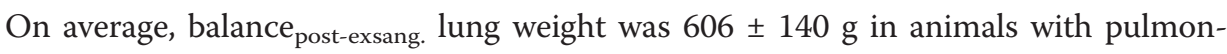
ary oedema $(n=11)$ and $263 \pm 55 \mathrm{~g}$ in those without pulmonary oedema $(n=24)$. Absolute measurement errors were not associated with (mean) lung weight $(r=0.16)$ $(p=0.36)$ and did not differ between animals with $(-112 \pm 45 \mathrm{~g})$ or without $(-110 \pm$ 27 g) pulmonary oedema $(p=0.88)$. Diversely, relative measurement errors were smaller in animals with $(-19 \%$; limits of agreement $-36 \%$ and $-3 \%)$ than in those without $(-43 \%$; limits of agreement $-61 \%$ and $-24 \%)$ pulmonary oedema $(p<0.01)$. 


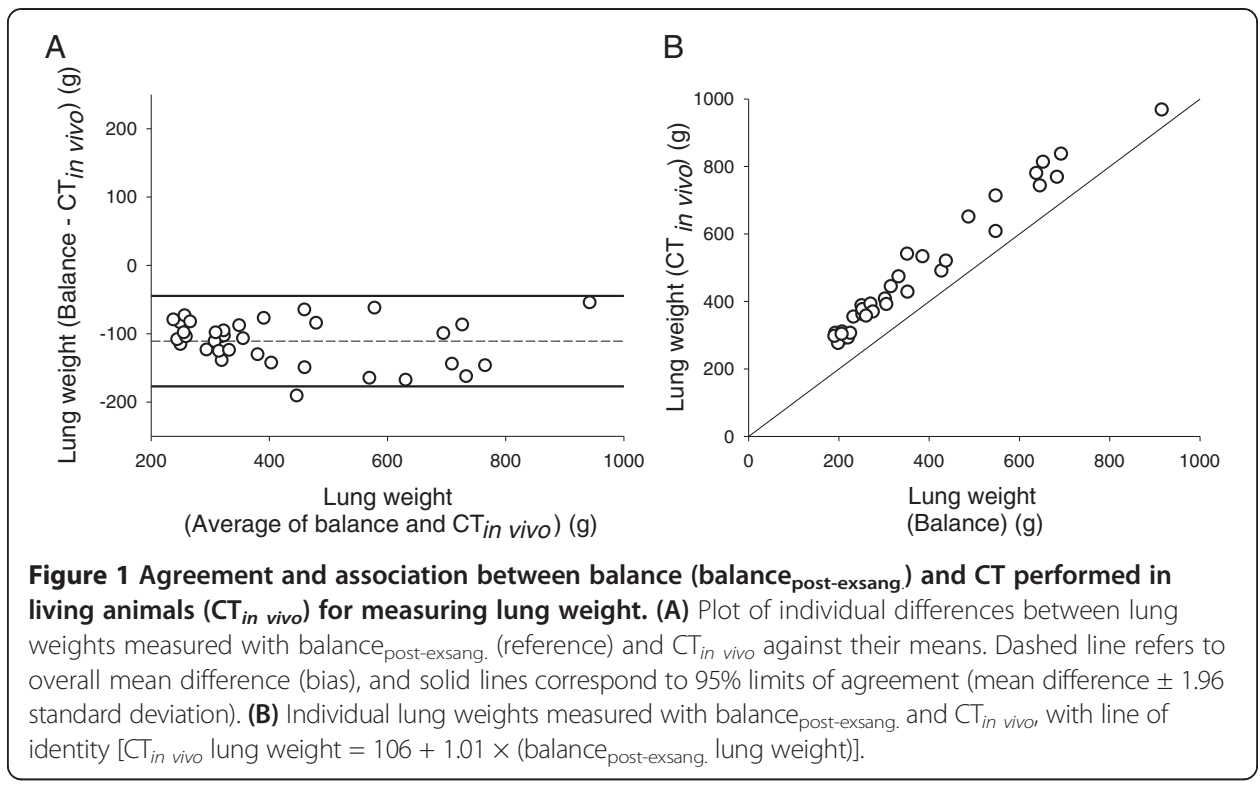

\section{Validation of $\mathrm{CT}$ performed after exsanguination ( $\mathrm{CT}_{\text {post-exsang. }}$ ) for measuring lung weight}

In 14 pigs (three with pulmonary oedema), lung weight was $342 \pm 165 \mathrm{~g}$ when mea-

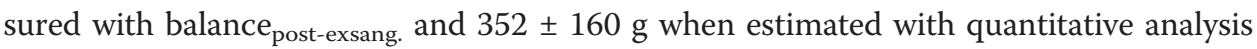
of $\mathrm{CT}_{\text {post-exsang. }}(p=0.02)$. Bias was $-9 \mathrm{~g}(-4 \%)$ and limits of agreement were -36 $(-11 \%)$ and $17 \mathrm{~g}(3 \%)$ (Figure 2a). Percentage error was 15\% and coefficient of correlation was $0.99(p<0.0001)$ (Figure $2 \mathrm{~b})$.

On average, balance $e_{\text {post-exsang. }}$ lung weight was $640 \pm 11 \mathrm{~g}$ in animals with pulmonary oedema $(n=3)$ and $261 \pm 42 \mathrm{~g}$ in those without pulmonary oedema $(n=11)$. Absolute measurement errors were not associated with (mean) lung weight $(r=0.41)(p=0.15)$
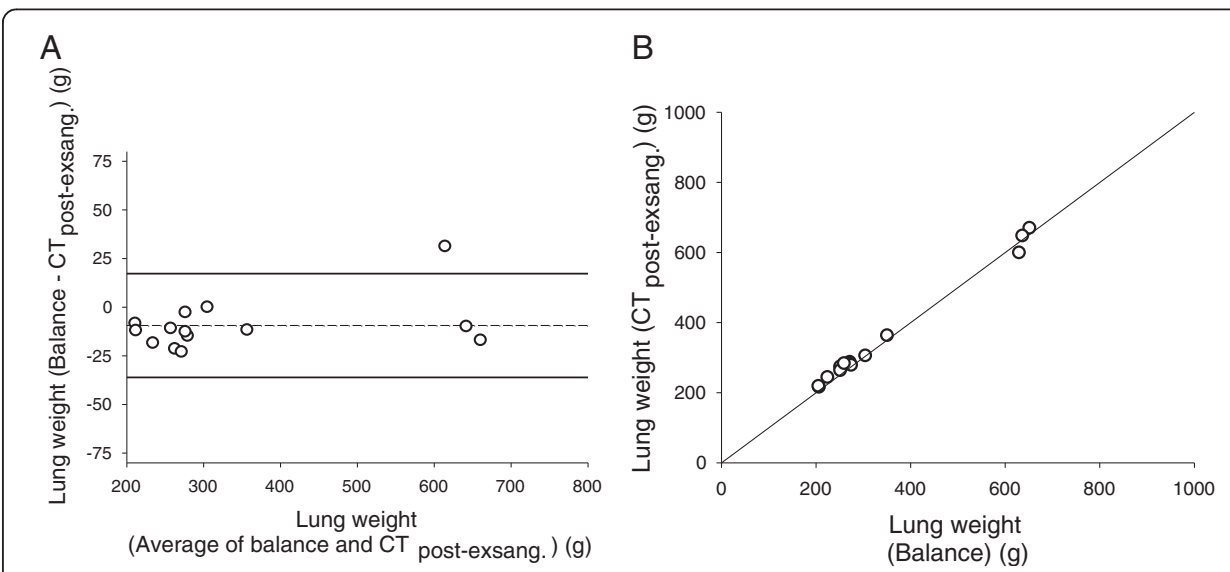

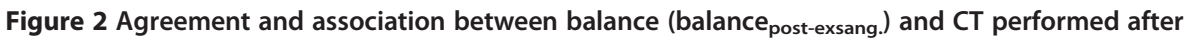
exsanguination ( $\mathrm{CT}_{\text {post-exsang. }}$ ) for measuring lung weight. (A) Plot of individual differences between

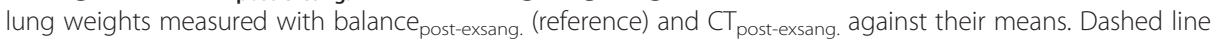
refers to overall mean difference (bias), and solid lines correspond to $95 \%$ limits of agreement (mean

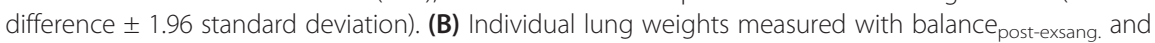
$C \mathrm{~T}_{\text {post-exsang, }}$ with line of identity $\left[C T_{\text {post-exsang. lung weight }}=22+0.96 \times\right.$ (balance $\left.\left._{\text {post-exsang. lung weight }}\right)\right]$. 
and did not differ between animals with $(-1 \pm 26 \mathrm{~g})$ or without $(-12 \pm 7 \mathrm{~g})$ pulmonary oedema $(p=0.12)$.

The volume of blood aspirated during exsanguination was 1,049 $\pm 283 \mathrm{ml}$. The density of blood (measured in three animals) was $1.01 \mathrm{~g} / \mathrm{ml}$.

In 13 animals that underwent both $\mathrm{CTs}, \mathrm{CT}_{\text {in vivo }}$ overestimated lung weight by $105 \pm$ $32 \mathrm{~g}$ compared to $\mathrm{CT}_{\text {post-exsang. }}$ and by $117 \pm 32 \mathrm{~g}$ compared to the balance $(p=0.23)$.

\section{Repeatability and reproducibility of quantitative analysis of thorax CT}

Coefficients of intra- and inter-subject variability were $2.4 \%$ and $4.2 \%$, respectively, for healthy lungs and $2.2 \%$ and $0.3 \%$, respectively, for oedematous lungs.

\section{Discussion}

Compared to gravimetry, quantitative analysis of thorax CT accurately measures the weight of lungs of exsanguinated animals $\left(\mathrm{CT}_{\text {post-exsang: }}\right.$ bias $-4 \%$; percentage error $15 \%)$. However, it largely overestimates the weight of lungs of living animals $\left(\mathrm{CT}_{\text {in vivo: }}\right.$ : bias $-35 \%$; percentage error $35 \%$ ) as it includes pulmonary blood.

Other authors have shown that CT properly quantifies the weight of inanimate objects [8], artificial lung models [13], exsanguinated [14] and frozen [15] lungs and surgically excised pulmonary lobes [16]. Results acquired in vivo can be less accurate. For instance, in previous studies, the weight of the right hepatic lobes differed by $20 \%$ to $35 \%$ when measured pre-operatively with CT (in vivo) or intra-operatively with a balance (ex vivo). One plausible explanation for this discrepancy is blood volume: measurements taken before surgery included blood, whereas those obtained after graft procurement did not $[17,18]$. In our study, lung weight measured with $\mathrm{CT}_{\text {in }}$ vivo (before exsanguination) exceeded by around $100 \mathrm{~g}$ that obtained with $\mathrm{CT}_{\text {post-exsang. }}$ or the balance (after exsanguination). Pulmonary blood is around $5 \mathrm{ml} / \mathrm{kg}$ of body weight in pigs [19] and represents $10 \%$ to $15 \%$ of the total blood volume in mammals [20] (normal values in humans: 220 to $270 \mathrm{ml} / \mathrm{m}^{2}$ of body surface area [21]). Therefore, it likely approximated $100 \mathrm{ml}$ in 20-kg pigs that exsanguinated, on average, $1 \mathrm{l}$ of blood. Since blood density was $1 \mathrm{~g} / \mathrm{ml}$, pulmonary blood weight of animals included in our experiments was probably around $100 \mathrm{~g}$ and thus explains the bias reported above. Of note, measurement error was the same even in animals with (inflammatory) pulmonary oedema as if changes in lung weight induced by mechanical ventilation mainly reflected changes in extravascular water content [22]. As a consequence, relative measurement error was as low as $19 \%$ in animals with pulmonary oedema.

In line with the model described so far, differences between computed tomography and gravimetry virtually disappeared when they both measured blood-free lung weights $\left(\mathrm{CT}_{\text {post-exsang. }}\right.$ vs. balance post-exsang. $)$. To further corroborate this finding, two other animals underwent thorax $\mathrm{CT}_{\text {in vivo }}$ and were then sacrificed but not exsanguinated to allow intravascular blood clotting. Two hours later, lungs were excised with minimal blood loss. As expected, results of quantitative analysis of thorax $\mathrm{CT}_{\text {in vivo }}$ differed by only $24 \mathrm{~g}(5 \%)$ and $11 \mathrm{~g}$ (3\%) from those obtained with the balance as both methods measured the weight of blood-filled lungs. 
Some limitations of the study deserve a comment. First, sample size was limited due to inconstant availability of $\mathrm{CT}$, some unexpected early deaths and completion of research projects to which animals were originally assigned. Accuracy of $\mathrm{CT}_{\text {post-exsang. }}$ was evaluated only in three animals with pulmonary oedema, and therefore, results should be interpreted with caution. Second, the volume of blood withdrawn from animals was quite variable, possibly because heparin was not used to prevent post-mortem thrombosis. This may be the reason why percentage error of lung weight estimated with $\mathrm{CT}_{\text {in vivo }}$ was as high as $35 \%$. Third, the use of thorax $\mathrm{CT}$ in clinical practice requires transfer of patients to radiology [23] and exposure to ionising radiations [24]. In addition, quantitative analysis is complex and time consuming. However, low-dose exams [25] and simplified analysis [26,27] may limit risks and expense. Moreover, quantitative analysis of thorax CT does not only measure lung weight but also characterises patients with acute respiratory failure [28], assesses distribution of ventilation [29], quantifies pulmonary inhomogeneities [30] and predicts response to therapy [31].

\section{Conclusions}

When performed on living subjects, quantitative analysis of thorax CT scan constantly overestimated lung weight as it included pulmonary blood (whereas the balance did not). In bloodless conditions, it provided accurate, reproducible and repeatable results.

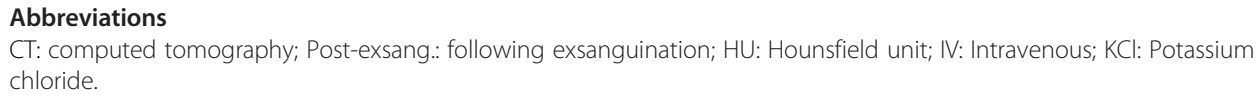

\section{Acknowledgements}

We are indebted to Luciano Lombardi (Dipartimento di Radiologia, Fondazione IRCCS Ca' Granda - Ospedale Maggiore Policlinico, Milan, Italy) and Dr. Maurizio Rozza (Dipartimento di Fisica Sanitaria, Fondazione IRCCS Ca' Granda - Ospedale Maggiore Policlinico, Milan, Italy) for their precious technical support. Preliminary results were presented at the 24 th Simposio Mostra Anestesia Rianimazione Terapia intensiva (SMART) in Milan, May 2013.

\section{Author details \\ 'Dipartimento di Anestesia, Rianimazione ed Emergenza Urgenza, Fondazione IRCCS Ca' Granda - Ospedale Maggiore Policlinico, Via F. Sforza 35, 20122 Milan, Italy. ${ }^{2}$ Dipartimento di Fisiopatologia Medico-Chirurgica e dei Trapianti, Università degli Studi di Milano, Via della Commenda 16, 20122 Milan, Italy.}

Received: 1 July 2014 Accepted: 10 November 2014

Published online: 05 December 2014

\section{References}

1. Protti A, Cressoni M, Santini A, Langer T, Mietto C, Febres D, Chierichetti M, Coppola S, Conte G, Gatti S, Leopardi O, Masson S, Lombardi L, Lazzerini M, Rampoldi E, Cadringher P, Gattinoni L (2011) Lung stress and strain during mechanical ventilation: any safe threshold? Am J Respir Crit Care Med 183:1354-1362

2. Ashbaugh DG, Bigelow DB, Petty TL, Levine BE (1967) Acute respiratory distress in adults. Lancet 2:319-323

3. Gattinoni L, Caironi P, Cressoni M, Chiumello D, Ranieri VM, Quintel M, Russo S, Patroniti N, Cornejo R, Bugedo G (2006) Lung recruitment in patients with acute respiratory distress syndrome. N Engl J Med 354:1776-1786

4. Protti A, Chiumello D, Cressoni M, Carlesso E, Mietto C, Berto V, Lazzerini M, Quintel M, Gattinoni L (2009) Relationship between gas exchange response to prone position and lung recruitability during acute respiratory failure. Intensive Care Med 35:1011-1017

5. Gattinoni L, Pesenti A, Bombino M, Baglioni S, Rivolta M, Rossi F, Rossi GP, Fumagalli R, Marcolin R, Mascheroni M, Torresin A (1988) Relationships between lung computed tomographic density, gas exchange, and PEEP in acute respiratory failure. Anesthesiology 69:824-832 
6. Wegener $\mathrm{OH}$, Koeppe P, Oeser $\mathrm{H}$ (1978) Measurement of lung density by computed tomography. J Comput Assist Tomogr 2:263-273

7. Mull RT (1984) Mass estimates by computed tomography: physical density from CT numbers. Am J Roentgenol 143:1101-1104

8. Brenner DE, Whitley NO, Houk TL, Aisner J, Wiernik P, Whitley J (1982) Volume determinations in computed tomography. JAMA 247:1299-1302

9. Protti A, Andreis DT, Monti M, Santini A, Sparacino CC, Langer T, Votta E, Gatti S, Lombardi L, Leopardi O, Masson S, Cressoni M, Gattinoni L (2013) Lung stress and strain during mechanical ventilation: any difference between statics and dynamics? Crit Care Med 41:1046-1055

10. Protti A, Andreis DT, lapichino GE, Monti M, Comini B, Milesi M, Zani L, Gatti S, Lombardi L, Gattinoni L (2013) High positive end-expiratory pressure: only a dam against oedema formation? Crit Care 17:R131

11. Institute of Laboratory Animal Resources, Commission on Life Sciences, National Research Council (1996) Guide for the care and use of laboratory animals. National Academy Press, Washington

12. Bland JM, Altman DG (1986) Statistical method for assessing agreement between two methods of clinical measurement. Lancet 1:307-310

13. Denison DM, Morgan MD, Millar AB (1986) Estimation of regional gas and tissue volumes of the lung in supine man using computed tomography. Thorax 41:620-628

14. Henne $E$, Anderson JC, Lowe N, Kesten S (2012) Comparison of human lung tissue mass measurements from ex vivo lungs and high resolution CT software analysis. BMC Pulm Med 12:18

15. Hyde RW, Wandtke JC, Fahey PJ, Utell MJ, Plewes DB, Goske M (1989) Lung weight in vivo measured with computed tomography and rebreathing of soluble gases. J Appl Physiol 67:166-173

16. Sverzellati N, Kuhnigk JM, Furia S, Diciotti S, Scanagatta P, Marchianò A, Molinari F, Stoecker C, Pastorino U (2013) CT-based weight assessment of lung lobes: comparison with ex vivo measurements. Diagn Interv Radiol 19:355-359

17. Hwang S, Lee SG, Kim KH, Park KM, Ahn CS, Moon DB, Chu CW, Lee YJ, Min PC (2002) Correlation of blood-free graft weight and volumetric graft volume by an analysis of blood content in living donor liver grafts. Transplant Proc 34:3293-3294

18. Lemke AJ, Brinkmann MJ, Schott T, Niehues SM, Settmacher U, Neuhaus P, Felix R (2006) Living donor right liver lobes: preoperative $C T$ volumetric measurement for calculation of intraoperative weight and volume. Radiology 240:736-742

19. Kuno Y (1917) On the amount of blood in the lungs. J Physiol 51:154-158

20. Ugander M, Kanski M, Engblom H, Goetberg M, Olivecrona GK, Erlinge D, Heiberg E, Arheden H (2010) Pulmonary blood volume variation decreases after myocardial infarction in pigs: a quantitative and noninvasive MR imaging measure of heart failure. Radiology 256:415-423

21. Dock DS, Kraus WL, McGuire LB, Hyland JW, Haynes FW, Dexter L (1961) The pulmonary blood volume in man. J Clin Invest 40:317-328

22. Dreyfuss D, Basset G, Soler P, Saumon G (1985) Intermittent positive-pressure hyperventilation with high inflation pressure produces pulmonary microvascular injury in rats. Am Rev Respir Dis 132:880-884

23. Beckmann U, Gillies DM, Berenholtz SM, Wu AW, Pronovost P (2004) Incidents relating to the intra-hospital transfer of critically ill patients. Intensive Care Med 30:1579-1585

24. Berrington de González A, Darby S (2004) Risk of cancer from diagnostic X-rays: estimates for the UK and 14 other countries. Lancet 363:345-351

25. Chiumello D, Langer T, Vecchi V, Luoni S, Colombo A, Brioni M, Froio S, Cigada I, Coppola S, Protti A, Lazzerini M, Gattinoni L (2014) Low-dose chest computed tomography for quantitative and visual anatomical analysis in patients with acute respiratory distress syndrome. Intensive Care Med 40:691-699

26. Reske AW, Reske AP, Gast HA, Seiwerts M, Beda A, Gottschaldt U, Josten C, Schreiter D, Heller N, Wrigge H, Amato MB (2010) Extrapolation from ten sections can make $C T$-based quantification of lung aeration more practicable. Intensive Care Med 36:1836-1844

27. Chiumello D, Marino A, Brioni M, Menga F, Cigada I, Lazzerini M, Andrisani MC, Biondetti P, Cesana B, Gattinoni L (2013) Visual anatomical lung CT scan assessment of lung recruitability. Intensive Care Med 39:66-73

28. Goodman LR, Fumagalli R, Tagliabue P, Tagliabue M, Ferrario M, Gattinoni L, Pesenti A (1999) Adult respiratory distress syndrome due to pulmonary and extrapulmonary causes: $\mathrm{CT}$, clinical, and functional correlations. Radiology 213:545-552

29. Terragni PP, Rosboch G, Tealdi A, Corno E, Menaldo E, Davini O, Gandini G, Herrmann P, Mascia L, Quintel M, Slutsky AS, Gattinoni L, Ranieri VM (2007) Tidal hyperinflation during low tidal volume ventilation in acute respiratory distress syndrome. Am J Respir Crit Care Med 175:160-166

30. Cressoni M, Cadringher P, Chiurazzi C, Amini M, Gallazzi E, Marino A, Brioni M, Carlesso E, Chiumello D, Quintel M, Bugedo G, Gattinoni L (2014) Lung inhomogeneity in patients with acute respiratory distress syndrome. Am J Respir Crit Care Med 189:149-158

31. Caironi P, Cressoni M, Chiumello D, Ranieri M, Quintel M, Russo SG, Cornejo R, Bugedo G, Carlesso E, Russo R, Caspani L, Gattinoni L (2010) Lung opening and closing during ventilation of acute respiratory distress syndrome. Am J Respir Crit Care Med 181:578-586

doi:10.1186/s40635-014-0031-0

Cite this article as: Protti et al: Validation of computed tomography for measuring lung weight. Intensive Care Medicine Experimental 2014 2:31. 